Yuen, H.K., Fox, R., Sun, A. \& Deng, L. (2009). Course Management Systems in Higher Education: Understanding Student Experiences, Interactive Technology and Smart Education, 6(3), pp. 189-205.

\title{
Course Management Systems in Higher Education: Understanding Student Experiences
}

\author{
Allan YUEN, Robert FOX, Angie SUN \& Liping DENG \\ Center for Information Technology in Education, \\ Faculty of Education, The University of Hong Kong \\ Pokfulam Road, Hong Kong, Hong Kong SAR, China \\ Fax: (852) 25177194 Email: hkyuen@hkucc.hku.hk
}

\begin{abstract}
The course management system, as an evolving tool and innovation, is increasingly used to promote the quality, efficiency and flexibility of teaching and learning in higher education. However, the ways that course management systems can support and enhance the quality of teaching and learning needs further investigation. This paper describes findings of an exploratory study into undergraduate and postgraduate students' experiences of course management systems, and aims to provide insights into issues concerning the implementation of such systems in higher education. The exploration focuses on the following aspects: perceived usefulness of technologies for study; usage pattern of course management systems; students' perceptions of course management systems; user support preference; and self-reported experiences. Significant differences between academic levels of students are evident. Findings of the study shed light on issues concerning technology, pedagogy, and implementation strategies of course management systems in higher education.
\end{abstract}

Keywords: course management system; student experience; e-learning; higher education.

\section{Introduction}

The past two decades have witnessed the unprecedented growth of the Internet and an ensuing transformation in the educational landscape. The adoption of a wide variety of web-based tools has given rise to the trend of e-learning in education world-wide. Meanwhile, the increasing availability of wireless (Choi, et al., 2007) and mobile technology (Petrova, 2007) makes elearning even more ubiquitous and pervasive. The development of a course management system (CMS) or learning management system can be viewed as both the result and the impetus of this e-learning trend. As a software package, CMS provides "web-based tools, services, and resources to support teaching and learning processes for both online and blended delivery" (McConachie, Danaher, Luck, \& Jones, 2005). Often, CMSs have their presence in the sector of higher education, and their roles have evolved from course authoring tools to enterprise-level 
systems (Finkelstein, 2003). CMSs are increasingly used as a solution to promote the quality, efficiency and flexibility of teaching and learning in higher education.

As an evolving tool and innovation, CMS is used for a variety of purposes and in various ways and settings (McGee, Carmean, \& Jafari, 2006). Nevertheless, it remains arguable whether the CMS is an important tool to help transform higher education. McGee, Carmean, and Jafari (2006) summarize issues of CMS in three foci: to understand CMS and make better pedagogical choices, to inform CMS implementation with learning theory and intentional pedagogical design, and to define and design the next generations of CMS software environment.

However, many studies concerning e-learning have focused on practitioner perspective or course design and overlooked students' voices (Sharpe, Benfield, Lessner \& DeCicco, 2005). In our study, students' experiences are central. We investigate students' experiences of CMS across faculties within a comprehensive university in Hong Kong. The specific research questions that guide our exploration are: How do students experience CMS and other online technologies? What are the usage patterns of CMS? How do students perceive CMS utilities and support? In particular, we probed the possible differences between academic levels of students. We expect that this study can contribute to understanding students' experiences of using CMS, and possibly inform the decision-making process concerning successful implementation of CMS in higher education.

\section{Course Management System and Student Experience}

In recent years, CMS has become an integral part of infrastructure in higher education, especially with the introduction of enterprise-level CMS (Katz, 2003). According to the survey conducted by Harrington and associates (2004), more than 80 percent of higher education institutions in the US used CMS. CMS is not simply a tool for teaching and learning, but an integral part of education infrastructure in higher education (Katz, 2003). Educause Center for Applied Research (ECAR) conducted serial studies of undergraduate students' experience with technology and reported that with CMS, students' engagement level increased significantly over the past three years (Salaway, Caruso, Nelson, \& Dede, 2007).

Course management systems are difficult to define because they can encompass so much. As described by Morgan (2003), the major goal of a CMS is "to integrate a suite of teaching technologies into a powerful set of tools that make it easy for faculty to use technology in instruction" (p. 16). The genre of CMS technology can trace its roots to the mid- to late-1990s. Many of the early CMSs were created within higher education in direct response to the lack of tools that supported online teaching. For example, WebCT was conceived on the campus of the University of British Columbia, Blackboard at Cornell University, and ATutor at the University of Toronto. While some of these systems were transferred into the commercial sector, others have remained as homegrown institutional systems (Gibbons, 2005).

In spite of the large array of CMSs available, homegrown or commercial systems, they often

have similar functions. Commonly included within the functions of a CMS are synchronous and 
asynchronous communication tools, such as discussion board, online chat, and email. Organizational tools, including online calendar and syllabus, announcement board, and digital drop box, assist the instructor in managing the flow of information and content within the class. Through online exams and quizzes, grading tools, and tracking course site use by individual students, the CMS can also help to streamline student assessment. Within the CMS, students and faculty can share URLs and digital documents, including assigned reserve reading materials (Gibbons, 2005). Dabbagh and Bannan-Ritland (2005) categorized the common CMS features into five groups: communication tools (e.g. discussion board, chat, E-mail); content creation and delivery tools (e.g. assignment, course documents); administrative tools (e.g. calendar, announcements); learning tools (e.g. personal tasks, bookmarks); and assessment tools (e.g. grade book, quiz).

Much of the literature on e-learning has focused on teachers' experience and perceptions while students' voices are largely unheard and their experiences undocumented (Alexander, 2001; D'Angelo \& Woosley, 2007). In actuality, students have unique perspectives on classroom and school reality (Cook-Sather \& Shultz, 2001). Löfström and Nevgi (2007) observed a considerable discrepancy between teachers' and students' perceptions regarding online learning. Basically teachers had more positive assessment of students' learning than did students. Therefore, Cook-Sather (2002) advocated foregrounding students' voice in educational research, policy and practice. In addition, earlier works largely focused on specific technology tools in specific discipline areas. A holistic approach that looks into the use of multiple tools across disciplines in higher education was rarely employed (D’Angelo \& Woosley, 2007). To address these research gaps, we scrutinized the use of CMS amongst undergraduate as well as postgraduate students across subject disciplines.

Several general frameworks of e-learning have been developed to understand, analyze and assess students' experiences. For instance, Levy (2006) proposes a conceptual model to evaluate effectiveness of the e-learning system from the perspective of learners. The four dimensions are: learners' satisfaction, perceived value of the system, attitude and behavior/usage. Hiltz (1994) highlights three categories of variables that influence students' acceptance of technology: technology (e.g. user-friendliness), courses, and student characteristics. Cheung and Huang (2005) propose a framework to assess Internet usage in higher education. Centering on students' perspective, their study explores the following four dimensions: organizational and individual factors (e.g. support, Internet skills); perceptions and attitudes (e.g. perceived usefulness, enjoyment); Internet usage (e.g. frequency, tools, task); and Internet impacts (e.g. on learning and future career). Similarly, Concannon, Flynn and Campbell (2005) summarize four types of factors that influenced students' experience with information and communication technologies: individual factors such as prior experience, attitude and self-efficacy; support factors including peer encouragement and tutor support; lecture/module factor such as grading, reward structures; and university factors including technical support, resource availability and accessibility. These four frameworks are representing different approaches to understand students' experiences in connection to e-learning. The factors and variables identified in these studies provide a useful list to be considered in our exploration. 
The RIPPLES model (Surry, Ensminger \& Haab, 2005) appears to be "a broad theoretical ICT adoption and implementation framework" (Benson and Palaskas, 2006; p.551) potentially useful for considering the evaluation of CMS. This comprehensive model covers a range of factors for consideration including resources, infrastructure, people, policies, learning, evaluation and support. The present study focuses on the third element of that model, i.e. "people" which refers to "the essential role that the needs, hopes, values, skills, and experiences of the people who will use an innovation play in the successful integration of an innovation" (Surry, Ensminger and Haab, 2005; p. 328). With consideration of the aforementioned studies, we thus stressed the following aspects in the present study: perceived usefulness of technologies (Davis, 1989) for study; usage pattern of course management systems; student perceptions of CMS; user support preference; and self-reported experiences.

\section{Methods}

This study aims to investigate students' experiences in using CMS within a university. A campus-wide survey was conducted in both electronic and paper-based formats. The construction of the questionnaire was guided by the aforementioned research and literature, and consisted of five parts: perceived usefulness of technologies for study, usage pattern of course management systems, student perceptions of CMS, user support preference, and self-reported experiences. The first four sections were closed-ended or scaled questions, whereas the fifth section was an open-ended question (Liao, Lu and Yi, 2007) to elicit students' positive and negative experience in using CMS.

The survey was conducted in a Hong Kong university. About $45 \%$ of academic staff in the university came from overseas. The student population of about 20,000 was located in 10 faculties (Architecture, Arts, Business and Economics, Dentistry, Education, Engineering, Law, Medicine, Science, and Social Sciences), with two-thirds undergraduate students and one-third postgraduate students. The university has not adopted one centralized CMS university-wide, and more than one CMS is being used across the various faculties. In terms of history of CMS implementation, some faculties have had a long involvement in using various educational technologies before moving to the implementation of a CMS, whereas others have had only a modest previous involvement with educational technologies. Thus, the CMS deployment might be different among faculties.

Table 1 Demographic information of the participants

\begin{tabular}{ll}
\hline Gender & $456(50.4 \%)$ \\
Female & $435(48.1 \%)$ \\
Male & $13(1.4 \%)$ \\
Missing & $719(79.5 \%)$ \\
\hline Level of Study & $185(20.5 \%)$ \\
Undergraduate &
\end{tabular}

$N=904$ 
Data were collected from March to April 2007. Students were able to access the survey either through the online platform or through paper based survey distributed around the campus. Students were checked against their computer IP address and unique student number to avoid either repetitive or fraudulent entries. We received 926 survey responses of which 904 were valid and used in the data analysis. The respondents were from a total of ten faculties that include undergraduate and postgraduate students with either full-time or part-time status. There were a total of 456 female respondents and 435 male respondents (Table 1). We received the highest number of responses from the Faculty of Science, Arts and Engineering, the larger faculties of the university in terms of student population.

\section{$4 \quad$ Results}

The major findings of the study are described in six sections as follows.

\subsection{Perceived usefulness of technologies for study}

We believe that CMS should not be studied in isolation, and therefore we also took into consideration students' general experiences with other technologies. Firstly, we asked students to specify the online technologies they used and indicate their usefulness for study purposes. Generally students rated as more useful those technologies they used more often. Email, Instant Messenger (IM) and Wiki were among the technologies most used by students. Students also rated these as the three most useful technologies for their studies (Table 2). Particularly, email received the highest use and students found it the most valuable technology.

Table 2 Technologies that students have used and their perceived usefulness for study

\begin{tabular}{llll}
\hline Technologies & \% of student use & \multicolumn{2}{l}{ Perceived usefulness } \\
\cline { 3 - 4 } & & Mean & $S D$ \\
\hline Email & $95.0 \%$ & 3.49 & 0.59 \\
Instant Messenger & $75.7 \%$ & 3.04 & 0.70 \\
Wiki & $63.9 \%$ & 3.43 & 0.62 \\
Blog & $62.1 \%$ & 2.44 & 0.77 \\
Voice Over IP (VoIP) & $26.1 \%$ & 2.44 & 0.74 \\
RSS & $17.0 \%$ & 2.52 & 0.76 \\
Social-Bookmarking & $11.5 \%$ & 2.56 & 0.79 \\
\hline
\end{tabular}

$\mathrm{N}=904$; Perceived usefulness scale: $1=$ strongly disagree, $2=$ disagree, $3=$ agree, $4=$ strongly agree

Although Wiki was less used than IM, it was perceived as more useful with mean scores 3.43 and 3.04 respectively. One reading of this would be that Wiki is helpful in doing assignments and research for information retrieval. Blog was also one of the frequently used technologies with $62.1 \%$ of students having used it. However, students did not think it useful in their studies. 
Generally, blogging seemed to be less used for teaching and learning purposes, and as a result, students might not have seen any use for blogging in their studies.

Students at different levels of study also had usage preferences in Wiki, Blog and IM technologies (Table 3). More undergraduates used IM, Blog and Wiki than the postgraduates. Such technologies are mainly for information retrieval and communication purposes. In comparison, more postgraduates had used RSS and social bookmarking than had undergraduates. It seems these two technologies are useful in postgraduate studies. Though gender difference is not a focus of the present study, the findings show significant gender difference in using Wiki. More male than female students used Wiki $\left(\chi^{2}=14.47, d f=1, p<.001\right)$. However, the reason for the gender difference is not particularly clear.

Table 3 Technologies used by students from different level of study

\begin{tabular}{ll}
\hline Technologies & $\chi^{2}$ \\
\hline More undergraduates have used & $22.12^{* *}$ \\
IM & $12.01^{*}$ \\
Blog & $21.40^{* *}$ \\
Wiki & \\
More postgraduates have used & $9.39^{*}$ \\
RSS & $8.03^{*}$ \\
Social Bookmarking &
\end{tabular}

$\mathrm{N}=889, d f=1 ;{ }^{*} p<.01, * * p<.001$

Independent sample t-test reveals that undergraduate students perceived Wiki as more useful in their studies than did postgraduate students. Wiki is probably a good source for undergraduates seeking quick definitions and information in general. On the other hand, postgraduates perceived email, blog, RSS, social book-marking and VoIP as more useful in their studies than did undergraduates (Table 4).

Table 4 Perceived usefulness of the technologies by students from different level of study

\begin{tabular}{|c|c|c|c|c|c|}
\hline \multicolumn{2}{|l|}{ Technologies } & Mean & $S D$ & $\mathrm{~N}$ & $t$ \\
\hline \multicolumn{6}{|c|}{ Undergraduates rated more useful in their studies } \\
\hline \multirow[t]{2}{*}{ Wiki } & Undergraduates & 3.46 & 0.74 & 524 & \multirow[t]{2}{*}{$2.61 * *$} \\
\hline & Postgraduates & 3.29 & 0.77 & 108 & \\
\hline \multicolumn{6}{|c|}{ Postgraduates rated more useful in their studies } \\
\hline \multirow[t]{2}{*}{ Email } & Undergraduates & 3.47 & 0.59 & 703 & \multirow[t]{2}{*}{$-3.07 * *$} \\
\hline & Postgraduates & 3.62 & 0.57 & 182 & \\
\hline \multirow[t]{2}{*}{ Blog } & Undergraduates & 2.41 & 0.77 & 513 & \multirow[t]{2}{*}{$-2.63 * *$} \\
\hline & Postgraduates & 2.62 & 0.79 & 109 & \\
\hline \multirow[t]{2}{*}{ RSS } & Undergraduates & 2.44 & 0.79 & 180 & \multirow[t]{2}{*}{$-2.74 * *$} \\
\hline & Postgraduates & 2.74 & 0.67 & 65 & \\
\hline Social & Undergraduates & 2.49 & 0.75 & 136 & $-2.44 *$ \\
\hline Bookmarking & Postgraduates & 2.79 & 0.86 & 53 & \\
\hline VoIP & Undergraduates & 2.38 & 0.72 & 245 & $-2.94 * *$ \\
\hline
\end{tabular}




\begin{tabular}{lllll} 
& Postgraduates & 2.66 & 0.79 & 77 \\
\hline$* p<.05, * * p<.01$ & & & &
\end{tabular}

\subsection{Usage pattern of Course Management Systems}

Seven hundred and sixty-nine students responded "yes" to the question of whether they had ever used a course management system or learning management system. Among these students, WebCT was the one most used (Table 5). Students also perceived WebCT as the most comfortable CMS.

Table 5 Types of CMS students have used and their perceived comfort level of use

Types of CMS Number of responses Perceived comfort level

\begin{tabular}{llll}
\hline & & Mean & $S D$ \\
WebCT & 740 & 3.00 & 0.68 \\
ILN & 202 & 2.90 & 0.73 \\
Moodle & 104 & 2.56 & 0.69 \\
\hline
\end{tabular}

Perceived comfort level: $1=$ strongly disagree, $2=$ disagree, $3=$ agree and $4=$ strongly agree (more than one response was allowed in this question); ILN (Interactive Learning Network) is a homegrown CMS

Apart from the above popular CMSs, some students indicated they used other CMSs including: departmental or course websites maintained by individual departments, Blackboard, FirstClass, eClass, Knowledge Forum, Classman, Sakai, IVLE and ITaCS. Student experience of CMS usage varied, as shown in Table 6, which depicts students' CMS usage.

Table 6 CMS Usage

\begin{tabular}{ll}
\hline How long have you been using a CMS? & \\
Less than 1 year & $40.4 \%$ \\
1-2 year & $36.7 \%$ \\
3 years or more & $22.9 \%$ \\
\hline How often do you use a CMS? & \\
Daily & $25.2 \%$ \\
Weekly & $52.9 \%$ \\
Several times a year & $21.9 \%$ \\
\hline
\end{tabular}
$\mathrm{N}=769$

CMS functions are similar across different systems. Students were asked to check the CMS functions that they had used. Most of the students had used CMS to access course materials such as downloading lecture notes or references. Table 7 shows the percentages of students using different CMS functions.

Table 7 CMS functions used by students

CMS functions used $\quad$ Percent




\begin{tabular}{lc}
\hline Access to course materials & 91.4 \\
Course announcement & 80.3 \\
Submitting assignments and receiving online feedback & 64.7 \\
Class email to communicate with peers and instructors & 45.9 \\
Quiz/test & 41.1 \\
Discussion forum to exchange ideas with peers and instructors & 34.2 \\
Course evaluation & 18.4 \\
\hline
\end{tabular}

$\mathrm{N}=769$; More than one answer was allowed in this question

Significant differences were evident between undergraduate and postgraduate students over the use of CMS functions. It seems undergraduate curriculum has a higher emphasis on assessment, and more undergraduate students reported the use of quiz/test than did postgraduate students $\left(\chi^{2}=9.35, d f=1, p<.01\right)$. In contrast, more postgraduate students reported use of the discussion forum than did undergraduate students $\left(\chi^{2}=28.11, d f=1, p<.001\right)$. It is probable that postgraduate students have more need of a platform to exchange ideas and knowledge, and collaborate with peers.

\subsection{Student Perceptions of CMS Utilities}

Students were asked to respond to the statements (Table 8) concerning their perceptions of using CMS. The statements describe a set of common CMS utilities, such as resources access, organizing work and communicating with each other. The top three items that received the highest ratings from students were: enable convenient access to course materials, useful in my study, and saves my time.

Table 8 Student perceptions of CMS utilities

CMS Utilities Perception of CMS Utilities

\begin{tabular}{lll}
\hline & Mean & $S D$ \\
\cline { 2 - 3 } Enable convenient access to course materials & 3.32 & 0.67 \\
Useful in my study & 3.04 & 0.59 \\
Saves my time & 2.79 & 0.71 \\
Has enough functions to meet my needs & 2.58 & 0.70 \\
Facilitates exchange of ideas with peers and instructors & 2.56 & 0.77 \\
Helps organize my work & 2.51 & 0.74 \\
Facilitates staying in touch with other students & 2.24 & 0.76 \\
\hline
\end{tabular}

$\mathrm{N}=769$; Perception of CMS utilities: $1=$ strongly disagree, $2=$ disagree, $3=$ agree and $4=$ strongly agree

A set of one-way ANOVA reveals significant differences in student perceptions of all CMS utilities among students who access the CMS several times in a semester, and those who access CMS weekly and daily. Table 9 summarizes the effects of CMS usage on the perceptions of CMS utilities. It is perhaps not surprising that as students use CMS more frequently, they tend to perceive higher agreement regarding the CMS utilities. 
Table 9 Effects of CMS usage on the perceptions of CMS utilities

\begin{tabular}{|c|c|c|c|c|c|}
\hline \multirow[t]{2}{*}{ CMS Utilities } & \multicolumn{3}{|c|}{$\operatorname{Mean}(S D)$} & \multirow[t]{2}{*}{$F$} & \multirow[t]{2}{*}{$d f$} \\
\hline & $\begin{array}{l}\text { Several times } \\
\text { a semester }\end{array}$ & Weekly & Daily & & \\
\hline $\begin{array}{l}\text { Enable convenient access to } \\
\text { course materials }\end{array}$ & $3.11(0.71)$ & $3.32(0.68)$ & $3.48(0.59)$ & $13.69 * * *$ & $(2,763)$ \\
\hline Useful in my study & $2.80(0.64)$ & $3.01(0.57)$ & $3.29(0.51)$ & $33.91 * * *$ & $(2,762)$ \\
\hline Saves my time & $2.53(0.78)$ & $2.84(0.67)$ & $2.92(0.69)$ & $14.90 * * *$ & $(2,742)$ \\
\hline $\begin{array}{l}\text { Has enough functions to } \\
\text { meet my needs }\end{array}$ & $2.35(0.70)$ & $2.60(0.68)$ & $2.74(0.71)$ & $13.97 * * *$ & $(2,741)$ \\
\hline $\begin{array}{l}\text { Facilitates exchange of } \\
\text { ideas with peers and } \\
\text { instructors }\end{array}$ & $2.33(0.75)$ & $2.56(0.75)$ & $2.77(0.76)$ & $14.03 * * *$ & $(2,696)$ \\
\hline Helps organize my work & $2.29(0.71)$ & $2.53(0.74)$ & $2.67(0.72)$ & $11.83 * * *$ & $(2,713)$ \\
\hline $\begin{array}{l}\text { Facilitates staying in touch } \\
\text { with other students }\end{array}$ & $2.08(0.73)$ & $2.22(0.78)$ & $2.43(0.73)$ & $8.974 * * *$ & $(2,690)$ \\
\hline
\end{tabular}

Follow-up Post-hoc Scheffe tests indicated that students expressed significantly different perceptions of CMS utilities depending on whether they accessed the CMS daily, weekly, or several times in a semester. However, students who accessed CMS daily and weekly did not perceive a significant difference in the suggestions that CMS "helps in organizing my work," "has enough functions to meet my needs" and "saves my time." Also, students who accessed CMS weekly and several times a week did not perceive a significant difference in the notion that CMS "facilitates staying in touch with other students."

\subsection{User support preference}

Students were asked to indicate how often they received help from the listed sources (Table 10) when they experienced difficulty in using CMS. The results indicated that students often turned to their "peers and friends" for help, and least preferred to seek "technical support from computer centre" (Table 10), but sought support only "rarely" to "sometimes".

Table 7 Help and support for CMS use

\begin{tabular}{lll}
\hline Types of help and support & How often & \\
\cline { 2 - 3 } Peers and Friends & 2.91 & $S D$ \\
Technical support from Faculty or Department & 2.07 & 0.95 \\
Technical support from Computer Centre & 1.89 & 0.88 \\
Books, manuals or FAQs & 2.22 & 0.84 \\
\hline
\end{tabular}

$\mathrm{N}=766$; Four-point scale of how often: $1=$ never, $2=$ rarely, $3=$ sometimes, $4=$ often 
In the open-ended response, a few students mentioned that they would just explore the CMS on their own through trial-and-error or online help, and refer to their own notes and their own exploration. A few other students responded that they would ask their instructors for help. Three students commented that they had no problem with the use of CMS, and one of them even reported being the support for others. In accessing sources of help and support, there was significant difference in study levels for those getting help from peers and friends. Undergraduates frequently received more help from peers and friends than postgraduates $(t(682)=4.18, \mathrm{p}<.001$; Undergraduates: Mean=3.19, $\mathrm{SD}=0.70 ;$ Postgraduates: Mean=2.89, $\mathrm{SD}=0.74)$.

\subsection{Self-reported worst experience}

Students were asked in an open-ended question on the last part of the questionnaire to describe their worst and best experiences in using CMS. In general, descriptions of worst experiences were reported more frequently than best experiences. Table 8 summarizes five categories of problems that emerged from the analysis of student reports.

Table 8 Worst experience of CMS use

\begin{tabular}{ll}
\hline Types of problems & Number of codes \\
\hline Technological problems & 230 \\
Communal involvements and competition & 60 \\
Teachers are not keen & 50 \\
Problems of system design and features & 40 \\
Efficiency of administration and support & 24 \\
Total & 404 \\
\hline
\end{tabular}

Most students complained about technological problems with CMS, such as lack of speed and system errors that they encountered. Large numbers of students said the CMSs they used were slow. For example, a student wrote, "Slow uploading times for coursework submission. Sometimes the upload session failed or stalled during peak times (server overload)." Students also frequently complained about system errors; for example, "There are some bugs in the system and the calendar cannot save some of the events or the events disappear before the alarm rings/before the timeout." Students found the technical errors annoying. One student wrote, "Whenever I try to download a file from the WebCT, a bar appears at the top and I have to click it and choose 'download file', and then I am redirected to the main page, and I have to click, click and click to go to the file I want to download again from the beginning... I find it very inconvenient and a waste of my time." Technological issues contributed greatly to students' experiences of using a CMS. Students expected the CMS to be flawless to navigate and errorfree.

Some of the worst experiences were reported as originating within the students themselves, and concerned students' own preferences and practices and also their communal involvements. One student mentioned, "CMS depends heavily on the students who have joined; exchange of ideas is not possible with quiet students. I 'd written a msg on the discussion forum but nobody replied to me until one week later." As in the traditional classroom, different types of students participate in 
the forum, some of whom are quiet and some quite active. Students are sensitive to communal involvements in the CMS, and their participation would likely be reinforced by the culture and atmosphere. Students also expect instant and fast responses from other classmates, and are discouraged if there is no spontaneous response from other users. Some students perceived discussion on the CMS forum as unnecessary competition. As one student said, "Another problem is that some of the courses in my faculty are very competitive. Students tend to ask the lecturers questions privately so that other students will not know the problem and answers. That's why some courses don't use WebCT very often." Students might not want to share their knowledge and their reflections among peers. Quiet peers may be able to get all the answers and the collective knowledge without raising any questions or offering input. Therefore, the more active peers might feel unfairly obliged to actively participate in the discussion. They too might prefer to ask questions directly to the teachers instead of sharing questions and comments within the forum.

The third category of worst experiences that students reported concerned teachers. Since their usage and participation was also largely dependent on how their teachers used the CMS, students identified teaching and learning as an important element in CMS experience. Students complained about their teachers' practices, many of them reporting that their teachers had minimal use of the CMS. For example, a student said, "Professors are not very keen on using the system." When teachers were not actively participating in the CMS, and with low use of CMS capabilities, students also felt it was useless to participate in the CMS. Students reported that communication with teachers within CMS was neither easy and nor effective. A student said, "I cannot easily discuss anything with my lecturer in WebCT. Most of my lecturers did not put notes on HKU WebCT." The low participation of teachers in the CMS contributed to students' negative experiences in using CMS. It also affected their learning experiences in the courses.

Another complaint by the students concerned the system design and its features. Students thought that the CMS was not well-designed, not user friendly, features were not up-to-date and the CMS was generally not a piece of attractive software. One student said, "Actually, I think the forum functions seemed to be simple and not so useful." Students also wanted the CMS to be easy to use so they could find useful tools to help their study. "The interface is not user friendly, not enough tools available, e.g. dictionary, wiki." This statement indicated that the existing CMS did not match new technological developments. Students were actively in touch with new media such as wiki, blogs, and instant messenger. As illustrated in the previous section, students preferred to use these technologies inside as well as outside the CMS. Students believed such technologies were useful for study, and without their incorporation into the CMS, students found the system unattractive and less useful.

The worst experiences also included lack of administrative support. Access to CMS required that background administrative work be arranged. Before students could enroll and take part in the virtual community inside the CMS, their registration information from different university departments was often required. The process usually took place in the first few weeks of teaching while students could add or drop their designated courses. However, the add-and-drop action of course selection often created error or miscommunication between departments or platforms and caused problems in accessing the CMS. A student complained: "I cannot log in, because it needs 
two to three weeks to add me into a class after the add/drop period." The administrative support was not smooth enough, so students felt unhappy about not being able to access the CMS on time, a situation that could also slow down their learning progress.

This section has shown that the types of problems described in students' experiences with CMS are related to the institution's infrastructure, including technology and system features, the people involved i.e. students and teachers, and the support systems and framework required to ensure successful implementation (Surry et al., 2005).

\subsection{Self-reported best experience}

Student also reported their best experiences of CMS use. However, compared to their worst experiences, students reported best experiences much less frequently. Four categories were coded from the analysis of student responses (Table 9).

Table 9 Best experience of CMS use

\begin{tabular}{ll}
\hline Elements of best experience & Number of codes \\
\hline Accessibility and flexibility of CMS & 51 \\
Benefit for learning & 34 \\
Improve communication among teachers and students & 20 \\
User-friendliness of CMS & 2 \\
Total & 107 \\
\hline
\end{tabular}

The best experience most mentioned in using CMS related to its accessibility and flexibility. Many of the students treasured the convenience CMS provided for accessing the course materials online. For example, a student said: "I liked the ability to download the course materials well before the lecture took place. The best experience is I got the lecture notes for the whole year at a time, before the examination." It is interesting to note here that students might want to collect the lecture materials right before the examination. Lecture notes are particularly important for their exams. However, a question arises as to whether or not this convenience brings about good learning experiences for students. Does it mean students only access and download their course materials when an exam is approaching? Would the convenience encourage a higher rate of absenteeism at face-to-face lectures?

For occasional absentees, CMS provided a place to retrieve course materials and help students avoid missing important information. One of the students surveyed noted the usefulness of this CMS function: "When I was absent from the course once or twice for some reason, I could count on the WebCT to collect the material the teacher had given at the time of the class."

Some students also mentioned time saving in using CMS to access course materials and handle assignments. A student said, "Extremely convenient and fast to check grades or upload assignments. Makes it easier to time manage because all the information is @my fingertips." University students often have multiple roles and tight schedules, and find using CMS helpful in managing their coursework without going to campus to submit assignments or get feedback. 
The second most mentioned best experience was about the benefits of CMS. Students found CMS beneficial for their learning experience, as well as enriching of their learning process. Some students mentioned CMS as a centralized learning base. As one student reported, "all relevant materials are located in a place for reference, and therefore, it saves time when searching for useful information and fast feedback for all questions or problems placed in the forum."

Students also found CMS helpful in understanding their peers' learning as well as their own learning experience. One student wrote, "...it is really much more convenient than using e-mail; in addition, if we can all know the answers to the questions our classmates asked, it helps us in our study." Questions were asked and answered inside the CMS so that classmates could build their knowledge by actively responding to each other. Personal growth could also be visualized by tracking the learning history. A student commented: "I wrote my learning journal every week in the WebCT although it is required in a course work. I think that after a period of time, say a year, when I read my learning journal again, I hope I can find that I've improved from a freshman to a more mature student."

Students reported better communication between both teacher and student and between students as one of their best experiences in CMS use. One student said, “...we can obtain the course materials, receive auto reminders of assignment submission. What's more beneficial is that we can communicate with each other on the course and related topics." It is important to see how CMS connects the students into a learning community. Communication is not only of help in notifications and transferring information, but it also helps students relate better. Social integration is an important element in the learning process. Another student also commented that communication is faster on the CMS: "I can contact my tutor immediately and chat with her on a real-time basis." Fast communication contributed to the good experiences of CMS use as perceived by the students.

Only two of the students mentioned the technological factor as their best experience in using CMS. They both talked about the good user friendliness of CMS. However, considering the technological problems reported in the previous section, students generally did not find the current CMS technologically attractive.

Overall, the best experiences reported by students focused on CMS and learning. The same was also true in students' responses to CMS functions as presented in the previous sections.

\section{$5 \quad$ Discussion}

The student experiences prompted several observations of CMS implementation in higher education. These observations are connected to three aspects: technology, pedagogy, and implementation strategies (Collis \& Moonen, 2001).

\subsection{Technology}


In this study, CMS is a software system that is specially designed and marketed for teachers and students to use in learning and teaching (Morgan, 2003). By exploring the usage patterns and perceived utilities of CMS, we have attempted to understand students' experiences with such "special" technology. Are students satisfied with the technological features of the CMS they are using? Relevant to observations made by Concannon, Flynn \& Campbell (2005), we found that students' negative experiences with CMS centered on technological problems. It is important not to overlook the design of CMS functions or features when addressing student experiences, keeping in mind that those experiences will continue to change.

New technologies that students used regularly and found useful in their studies included Instant Messenger and Wiki, technologies that are communicative and interactive in nature. Recently, Web 2.0 advocated a new perspective of "mass collaboration," an approach that is successfully challenging traditional business designs and shaping our everyday life (Tapscott \& Williams, 2007). What this indicates is that instead of using the available CMS functions, students may expect to use other functions such as Wiki, Blog, and RSS to facilitate more collaboration and strengthen social networking. This preference for collaborative learning underlines the importance of Web 2.0 technologies to CMSs.

In terms of user support preference, it was obvious from the results that students often turn to their peers for help rather than seek technical help from faculties or computer centers. It is possible to speculate that easy-to-use should be a major principle for future development of CMS technology; that is, CMS should not be a complex system, but should have the capacity to be supported by peers without specific technical competence.

\subsection{Pedagogy}

CMS holds great promise both for increasing access to information and as a means of promoting learning and linking students and teachers in learning communities. Nonetheless, there is little empirical evidence that CMSs actually improve pedagogy (Morgan, 2003). The initial findings of student experiences reveal that CMS as an educational technology is in fact widely used by the majority of the students in their study, and they use it on a regular basis. It has most often been used for simple information retrieval and uploading. Students perceived "enable convenient access to course materials" as a key CMS utility. In terms of communicative CMS utilities, the findings did not show evidence that students either use these features often or find them particularly useful. Regarding student perceptions of CMS utilities, positive effects were shown on how often students use CMS. Although the challenge of the pedagogical impact of CMS still stands, we argue that the understanding of students' experiences with CMS would suggest possible avenues to improve pedagogical use of CMS apart from "convenient information access."

Another vital issue regarding learners' reaction and perceptions of using technology is individual differences. Many studies indicated that not all students benefit from online learning in the same way, and some do not benefit at all. For instance, Davis, Johnson and Vician (2005) found that low achieving students seemed to benefit most from online learning. Davis et al. asserted that the benefits of online learning were contingent on individuals and the technology involved. Liu and 
Chen (2005) focused on the relationship between learners' characteristics and their online knowledge sharing, and identified several learner attributes as key factors: personality, emotion, capability and attitude. Along the same line, Bressler and Bressler (2007) observed that students' self-esteem and self-efficacy were correlated with their success in online learning. Vonderwell and Zachariah (2005) noted that student's technology skills, previous online experience, learning styles and content expertise could influence their online participation. Similarly, the results of the current study demonstrate that "student characteristics", such as academic levels and perceptions, are important in affecting students' participation in CMS. Obviously, understanding students' experiences with CMS would facilitate teachers in designing activities in the pedagogical use of CMS.

\subsection{Implementation strategies}

Having the technology available and accessible is no guarantee that people will find it useful, find it easy to use, or even find it at all. However, the use of new technologies in teaching and learning is never solely a technical matter, as the new technologies are "used in a social environment and are, therefore, mediated by the dialogues that students have with each other and the teacher" (Bransford, Brown \& Cocking, 2000; p. 243). What factors affect the adoption and use of CMS? This is a crucial question about the implementation strategies of CMS. From the analysis of students' self-reported experiences, the results suggest four important factors associated with CMS use: infrastructure, people, support, and learning, as described in the "types of elements" (Section 4.5) and "elements of best experience" (Section 4.6).

Inoue (2007) reported that students' gender, ethnic background, academic status and age did not influence their perceptions of technology. Nonetheless, Gunn (2003) observed that male students were less likely to ask for assistance or recognize the need for help, and female students had lower confidence and less access to computers compared to male students. In this study, the findings indicate significant gender and academic level differences in CMS usage and perception. Thus, the factors of gender and academic level deserve further attention in the CMS implementation.

There is always the concern that potential benefits of CMS in facilitating classroom learning may not be fully realized when teachers themselves, for various reasons, do not adopt a more comprehensive use of CMS in their teaching. We suspected that one of the compelling reasons why students used these communicative platforms so rarely was because the usefulness of these features was not emphasized, encouraged or demonstrated by their teachers. In this study, students reported that some teachers were not keen on using CMS. The question therefore is whether there is in fact reluctance among academic staff to use CMS, and what the potential barriers are. How the university as a whole may address such problems could also lead to issues of staff development, an essential consideration in implementation strategies.

\section{Conclusion}


This is a small-scale study of a university in Hong Kong. Due to its small size, study results will not produce generalizations that can be applied directly in other institutions. Nevertheless, empirical studies in CMS implementation are relatively rare, and results of this study provide initial evidence to shed light on a number of issues concerning the implementation of CMS. Technology has evolved and become more central in higher education, and will continue to shape students' experiences and their expectations of learning and teaching. As argued by McCarthy and Wright (2004), "we don't just use or admire technology; we live with it" (p. 2). Technology is deeply embedded in everyday experience. It touches on many areas of students' lives, such as work, leisure, and learning. It brings fundamental changes in how people see themselves and their world. Thus, an account of students' experiences is essential to the design and implementation of CMS. This study serves as a starting point for exploring the role and impact of CMS in higher education.

\section{Acknowledgements}

This research is supported by a competitive research grant awarded by the Hong Kong Research Grants Council (Project No.: HKU 7452/06H).

\section{References}

Alexander, S. (2001). E-learning developments and experiences. Education + Training, 43(4/5), 240-248.

Benson, R. and Palaskas, T. (2006). Introducing a new learning management system: An institutional case study. Australasian Journal of Educational Technology, 22(4), 548-567.

Bransford, J.D., Brown, A.L. \& Cocking, R.R. (Eds.) (2000). How People Learn: Brain, Mind, Experience, and School, Washington, D.C.: National Academy Press.

Bressler, L. A., \& Bressler, M. E. (2007). The relationship between self-esteem and self-efficacy among distance learning students in Accounting Information Systems online classes. International Journal of Innovation and Learning, 4(3), 274-289.

Cheung, W., \& Huang, W. (2005). Proposing a framework to assess Internet usage in university education: An empirical investigation from a student's perspective. British Journal of Educational Technology, 36(2), 237-253.

Choi, Y. B., Abbott, T. A., Arthur, M. A., \& Hill, D. N. (2007). Toward a future wireless classroom paradigm. International Journal of Innovation and Learning, 4(1), 14-25.

Collis, B., \& Moonen, J. (2001). Flexible learning in a digital world: experiences and expectations. London, Kogan Page.

Concannon, F., Flynn, A., \& Campbell, M. (2005). What campus-based students think about the quality and benefits of e-learning. British Journal of Educational Technology, 36(3), 501-512.

Cook-Sather, A. (2002). Authorizing students' perspectives: Toward trust, dialogue, and change in education. Educational Researcher, 31(4), 3-14.

Cook-Sather, A., \& Shultz, J. (2001). Starting where the learner is: Listening to students. In J. Shultz \& A. Cook-Sather (Eds.), In our own words: Students' perspectives on school (pp. 117). Lanham, MD: Rowman \& Littlefield. 
D' Angelo, J. M., \& Woosley, S. A. (2007). Technology in the classroom: Friend or foe. Education, 127(4), 462-471.

Dabbagh, N., \& Bannan-Ritland, B. (2005). Online learning: Concepts, strategies, and application. Upper Saddle River, N.J.: Pearson, Merrill Prentice Hall.

Davis, F. D. (1989). Perceived usefulness, perceived ease of use, and user acceptance of information technology. MIS Quarterly, 13(3), 319-340.

Davis, L. R., Johnson, D. L., \& Vician, C. (2005). Technology-mediated learning and prior academic performance. International Journal of Innovation and Learning, 2(4), 386-401.

Finkelstein, J., \& Pittinsky, M. (2003). The evolving role of course management system providers in the transformation of Education: An interview with Blackboard's Matthew Pittinsky. The Technology Source, January/February.

Gibbons, S. (2005). Course management systems, Library Technology Reports, 41(3), pp. 7-11.

Gunn, C. (2003). Dominant or different: Gender issues in computer supported learning. Journal of Asynchronous Learning Networks, 7(1), 14-30.

Harrington, C. F., Gordon, S. A., \& Schibik, T. J. (2004). Course management system utilization and implications for practice: A national survey of department chairpersons [Electronic Version]. Online Journal of Distance Learning Administration, 7. Accessed April 2, 2007 from http://www.westga.edu/ distance/ojdla/winter74/harrington74.htm.

Hiltz, S. R. (1994). The virtual classroom: Learning without limits via computer networks. Norwood, N.J.: Ablex Pub. Corp.

Inoue, Y. (2007). University students' perceptions of computer technology experiences: Questionnaire results and analysis. In Y. Inoue (Ed.), Technology and diversity in higher education: New challenges (pp. 122-145). Hershey, PA: Information Science Publishing.

Katz, R. N. (2003). Balancing technology and tradition: The example of course management systems. Educause Review, 38(4), 48-59.

Levy, Y. (2006). Assessing the value of e-learning systems. Hershey, PA: Information Science Publishing.

Liao, K., Lu, J., \& Yi, Y. (2007). Research on humanised web-based learning model. International Journal of Innovation and Learning, 4(2), 186-196.

Liu, C. C., \& Chen, S. Y. (2005). Determinants of knowledge sharing of e-learners. International Journal of Innovation and Learning, 2(4), 434-445.

Löfström, E., \& Nevgi, A. (2007). From strategic planning to meaningful learning: Diverse perspectives on the development of web-based teaching and learning in higher education. British Journal of Educational Technology, 38(2), 312-324.

McCarthy, J. \& Wright, P. (2004). Technology as Experience, MA: The MIT Press.

McConachie, J., Danaher, P. A., Luck, J., \& Jones, D. (2005). Central Queensland University's course management systems: Accelerator or brake in engaging change [Electronic Version]. International Review of Research in Open and Distance Learning, 6. Accessed August 26, 2007 from http://www.irrodl.org/index.php/irrodl/article/view/219/869.

McGee, P., Carmean, C. \& Jafari, A. (2006). Managing Courses Defining Learning: What Faculty, Students, and Administrators Want, Educause, 41(4), 50-70.

Morgan, G. (2003). Faculty use of course management systems, Vol. 2, Research Study from the EDUCAUSE Centre for Applied Research (ECAR), Boulder, Colorado: EDUCAUSE.

Petrova, K. (2007). Mobile learning as a mobile business application. International Journal of Innovation and Learning, 4(1), 1-13. 
Salaway, G., Caruso, J. B., Nelson, M. R., \& Dede, C. (2007). The ECAR study of undergraduate students and information technology 2007. Boulder, Colo.: EDUCAUSE Center for Applied Research.

Sharpe, R., Benfield, G., Lessner, E., \& DeCicco, E. (2005). Final report: Scoping study for the pedagogy strand of the JISC learning programme. Unpublished internal report Accessed October 18, 2007, from http://www.jisc.ac.uk/uploaded_documents/scoping\%20study\%20final\%20report\%20v4.1.do $\underline{\mathrm{c}}$

Surry, D. W., Ensminger, D.C. \& Haab, M. (2005). A model for integrating instructional technology into higher education. British Journal of Educational Technology, 36(2), 327-329.

Tapscott, D. \& Williams, A.D. (2007). Wikinomics: How Mass Collaboration Changes Everything, London: Atlantic Books.

Vonderwell, S., \& Zachariah, S. (2005). Factors that influence participation in online learning. Journal of Research on Technology in Education, 38(2), 213-230. 